\title{
Humoral and cell-mediated immune responses of $d / d$ histocompatible pigs against classical swine fever (CSF) virus
}

\author{
Laurence PIRIOU ${ }^{\mathrm{a}}$, Sylvie CHEVALLIER ${ }^{\mathrm{a}}$, Evelyne HUTET $^{\mathrm{a}}$, \\ Bernard CHARLEY ${ }^{\mathrm{c}}$, Marie-Frédérique LE POTIER ${ }^{\mathrm{a} *}$, Emmanuel ALBINA $^{\mathrm{b}}$ \\ ${ }^{a}$ Agence Française de Sécurité Sanitaire des Aliments, Unité de Virologie et Immunologie Porcines, \\ BP 53, 22440 Ploufragan, France \\ b Centre de Coopération Internationale en Recherche Agronomique pour le Développement, \\ Programme Santé animale, TA 30/G, Campus International de Baillarguet, 34398 Montpellier, France \\ ${ }^{\mathrm{c}}$ Institut National de la Recherche Agronomique, Virologie et Immunologie Moléculaires, \\ 78352 Jouy-en-Josas, France
}

(Received 12 November 2002; accepted 10 February 2003)

\begin{abstract}
A better understanding of cell-mediated immune responses to classical swine fever virus (CSFV) is essential for the future development of improved vaccines. We analyzed the generation of cell-mediated and humoral immune responses in $\mathrm{d} / \mathrm{d}$ histocompatible pigs following CSFV infection or vaccination. Viral infection induced high $\mathrm{T}$ cell responses with high primary and secondary CTL activity correlated with high IFN- $\gamma$ production, whereas vaccination with a live vaccine followed by infection mainly induced neutralizing antibody but low cell-mediated responses. Moreover, high IgG1 response was associated with high IFN- $\gamma$ response following infection whereas a weak IFN- $\gamma$ response was related to a good IgG2 response but a low IgG1 production. These data could reflect Th1/Th2-like balance of immune responses depending upon immunization protocols, which has not yet been described in the pig. T-cell responses to CSFV were evidenced by CSFV-specific CD 25 upregulation on $\mathrm{CD} 4^{-} \mathrm{CD} 8^{+}$, but not on $\mathrm{CD} 4^{+} \mathrm{CD} 8^{-}$cells, which further illustrated the importance of CTL responses after infection. Our results indicated that generation of cell-mediated immune responses was much higher following intranasal/oral CSFV infection than after intramuscular vaccination, which implies that the capacity of new CSFV vaccines to induce higher $\mathrm{T}$-cell responses should be considered.
\end{abstract}

immunity / cytotoxicity / CSFV / d/d histocompatible pig

\section{INTRODUCTION}

Classical swine fever virus (CSFV) is a small enveloped RNA virus which belongs to the genus Pestivirus of the family Flaviviridae [33]. This virus causes acute, suba- cute or chronic disease in swine, which always leads to severe economic losses in the pig industry. In the past, vaccination against CSF using inactivated or attenuated live virus vaccines was used to control CSF outbreaks or chronic infection in

\footnotetext{
* Correspondence and reprints

Tel.: (33) 02960162 90; fax: (33) 02960162 94; e-mail: mf.lepotier@ ploufragan.afssa.fr
} 
domestic pig populations. Because these vaccines did not permit discrimination between vaccinated pigs and infected animals, the European Union moved its eradication program to a non vaccination and stamping out policy in 1990. However, due to changes in the biology of this virus and pig trading schemes, it has become more difficult to limit the impact of CSF outbreaks in some areas with high pig density, without using vaccination. It is therefore essential to develop subunit or "marker" vector vaccines to allow the vaccination of pigs in such outbreaks, limiting at the same time the restrictions on the trade of living pigs and pig meat products.

The understanding of cellular immune responses against viral infection is of major importance for the design of new and potent vaccines. So far, most studies have only concerned the humoral immune response of CSFV-infected animals. In infected pigs, a clear relationship between the presence of serum antibodies that neutralize the virus in vitro and protection against CSFV has been established in many studies suggesting that these neutralizing antibodies alone can control the replication of the virus in vivo [29]. However, in some instances where neutralizing antibodies were not detectable, a relative protection was observed suggesting a possible protective role for $\mathrm{T}$ cells [21]. Cellular immune responses, especially virus-specific cytotoxic T lymphocytes (CTL), have been shown to represent an important defense mechanism against African Swine Fever Virus (ASFV) infection in pigs [13]. These mechanisms have also been demonstrated for the Pestiviruses bovine viral diarrhea virus [3] and border disease virus [34]. Pauly et al. [15] demonstrated the existence of CSF-CTLs in peripheral blood mononuclear cells (PBMC) from immunized pigs. However, nothing has been reported so far about the kinetics and the magnitude of CTL activity after natural infection or vaccination. On the contrary, although CSFV-specific lymphoproliferative responses were demonstrated in CSFV- immune animals [9], other authors reported a decrease of PBMC proliferative responses in CSFV infected pigs [5, 24, 32]. In fact, this inhibitory effect observed in vitro may largely be due to the tropism of the virus for the immune system, in particular for PBMC [28], and the virus capacity to induce both severe lymphopenia and immunosuppression.

The objective of this study was to analyze in detail the kinetics of T-cell responses, including CTL and cytokine production, against CSFV in histocompatible d/d pigs. CSFV infection induced stronger T-cell responses than vaccination with a live virus followed by challenge infection, which suggests that further efforts should be made to improve the capacity of CSFV vaccines to induce higher T-cell responses.

\section{MATERIALS AND METHODS}

\subsection{Viruses and titration}

CSFV Thiverval attenuated strain $\left(\right.$ Coglapest $^{\circledR}$ vaccine, titer: $10^{3.8}$ TCID $_{50}$ ) was kindly supplied by CEVA-Phylaxia, Budapest, Hungary. CSFV virulent Alfort strain (titer: $10^{5} \mathrm{TCID}_{50}$ ) was obtained from Hannover (Germany) and was propagated in the pig kidney cell line PK-15.

\subsection{Animals and experimental protocols}

\subsubsection{Animals}

Pigs of the $d / d$ haplotype were kindly supplied by H. Salmon and P. Lechopier (INRA, Nouzilly, France).

\subsubsection{CSF V immunization protocols}

Two pigs of the $d / d$ haplotype, hereafter referred to as the challenged ("chall") pigs, were infected by the intranasal route with a subacute dose of the CSFV Alfort strain $\left(10^{4.5} \mathrm{TCID}_{50}\right)$, to "mimic" a natural route of 
infection. Two other $\mathrm{d} / \mathrm{d}$ pigs were intramuscularly immunized (vaccination) with the Thiverval attenuated strain (coglapest ${ }^{\circledR}$ vaccine, $10^{3.8} \mathrm{PFU}$ ) followed by one intramuscular inoculation (challenge) of $10^{4.5}$ TCID $_{50}$ of the CSFV Alfort strain at week 3 . These two pigs served to induce strong and possibly both cell and antibodymediated immune responses to CSFV. They will be referred to as vaccinated and challenged ("vacc/chall") pigs. Two control pigs were not immunized and not inoculated. Clinical observations, body weight and temperature were monitored daily from days 0 to 74 post-vaccination and infection (PI). Blood was collected weekly for preparation of PBMC and serum. The investigation of humoral and cellular immunity was achieved in all pigs with the methods described below. Presence of viral RNA was assayed by RT-PCR as described below. Clinical signs after challenge were monitored.

\subsection{Laboratory investigations}

\subsubsection{CSFV antibody titration}

Serum samples were tested for the presence of neutralizing antibodies against CSFV using a neutralizing immunofluorescence test already described $[11,20]$.

Titration of anti-CSFV IgA, IgG, IgG1 and IgG2: Anti-CSFV serum antibodies $(\mathrm{Ab})$ were detected by indirect ELISA, using microplates coated with whole CSFV antigens (Platelia hog cholera, Biorad, France). The plates were first washed in PBS- $0.05 \%$ Tween $80-1 \%$ dried skimmed milk. Then test-sera diluted to $1 / 100$ in PBS-0.05\% Tween 80 were added and incubated for $1 \mathrm{~h}$ at $37^{\circ} \mathrm{C}$. After washing, the wells were filled for $1 \mathrm{~h}$ at $37^{\circ} \mathrm{C}$ with either $100 \mu \mathrm{L}$ of $1 / 1000$ anti-IgG1 mAb or $100 \mu \mathrm{L}$ of $1 / 45000$ anti-IgG2 mAb or $100 \mu \mathrm{L}$ of $1 / 2000$ anti-IgG mAb or $100 \mu \mathrm{L}$ of $1 / 2000$ anti-IgA mAb (all mAb from Iddlo, Lelystad, The Netherlands). Then,
$100 \mu \mathrm{L}$ of $1 / 1000$ rabbit peroxidase-labeled anti-mouse IgG (Jackson immunoresearch, Pennsylvania, USA) were added for $1 \mathrm{~h}$ at $37^{\circ} \mathrm{C}$. Optical densities (OD) were read at $450 \mathrm{~nm}$ after tetramethylbenzidine staining.

\subsubsection{Detection of CSF V mRNA}

CSFV in blood and serum was detected by nested RT-PCR as previously described by Mc Goldrick et al. [14].

\subsubsection{Preparation of peripheral blood mononuclear cells}

PBMC were isolated from heparinized blood by centrifugation on ficoll-hypaque (Pharmacia, Uppsala, Sweden). These cells were resuspended in complete medium until use or frozen in fetal bovine serum (FBS, Dutscher, F) $-10 \%$ DMSO for later use. Complete medium was constituted of RPMI 1640 (Gibco-BRL,UK) supplemented with $10 \%$ FBS, 1 mM sodium pyruvate (Sigma, St Louis, MO, USA), 100 UI/ $\mathrm{mL}$ penicillin (Sigma), $0.1 \mathrm{mg} / \mathrm{mL}$ streptomycin (Sigma) and 1\% glucose (Sigma).

\subsubsection{CSF V-specific cell proliferative response}

The proliferative response of PBMC after CSFV in vitro re-stimulation was measured by bromodeoxyuridine incorporation $[1,16]$. We adapted this method for use in flow cytometry and double or triple labeling in order to evaluate the specific proliferation of $\mathrm{B}$ and $\mathrm{T}$ cell sub-populations. PBMC $\left(3 \times 10^{5}\right.$ cells $)$ were incubated with $100 \mu \mathrm{L}$ of infectious virus $\left(3 \times 10^{7} \mathrm{TCID}_{50} / \mathrm{mL}\right.$ of cells) for 4 days at $37{ }^{\circ} \mathrm{C}$ with $200 \mu \mathrm{M}$ BRDU. The negative controls (medium) and positive controls (phytohaemagglutinine, $5 \mu \mathrm{g} / \mathrm{mL}$, Abbott, Illinois, USA) were prepared at the same time.

Phenotyping of PBMC was done using the following mAbs: anti-CD4 (74-12-4, 
IgG2b [17], anti-IL2R (231-3B2, IgG1, [2]), R-PE conjugated anti-CD8 (76-2-11, [17], Pharmingen, CA), anti-IgM (PIG45A, IgG2b, VMRD, Pullmann, WA, USA). Appropriate isotype control labeling was also included in the analysis (Mouse IgG2a, IgG2b and IgG1, Dako, Denmark). The detection of specific proliferating cells was performed in a five-step procedure : 1 . Cell labeling with anti-IgM $\mathrm{mAb}$ in order to differentiate $\mathrm{B}$ and $\mathrm{T}$ cells, or anti-CD4 and anti-CD8 to differentiate CD4 and CD8 T-lymphocytes, for $30 \mathrm{~min}$ on ice. 2. Incubation with isotype-specific conjugates (goat anti-mouse IgG2a-RPE and goat antimouse IgG2b-TC, CALTAG, Burlingame, CA, USA), again for $30 \mathrm{~min}$ on ice. 3. Cells were then fixed with $200 \mu \mathrm{L}$ of PBS-paraformaldehyde (PFA) $1 \%-0.5 \%$ Tween 20 during 4 or 5 days at $4{ }^{\circ} \mathrm{C}$. 4 . Degradation of DNA by the Dnase 1 (Amersham Pharmacia, UK) at 50 units/wells in Tris-HCL buffer for $30 \mathrm{~min}$ at $37^{\circ} \mathrm{C}$. 5. Revelation of $B R D U$ incorporation by mouse $\mathrm{mAb}$ antiBRDU (Becton Dickinson, San Jose, CA, USA) for $30 \mathrm{~min}$ on ice and by incubation with isotype specific conjugates (goat antimouse IgG1-FITC, CALTAG, Burlingame, CA, USA) for $30 \mathrm{~min}$ on ice. The acquisition of triple labeling was done on a FACsort (Analysis of the data using the Cellquest software, Becton Dickincton, San Jose, CA, USA).

\subsubsection{CSFV-specific cell activation response}

Activation of cells was revealed by the expression of the IL2 receptor (CD25) at the cell surface $[2,23]$.

A specific mAb anti-CD25 (anti IL2-R, 231-3B2, IgG1, [2]) and an appropriate isotype-specific goat anti-mouse IgG1-FITC conjugate (CALTAG, CA, USA) were used. PBMC expressing CD25 were monitored by flow cytometry. Cell phenotyping was also done by triple labeling as described above.

\subsubsection{Studies on cytokine profiles}

The Th1/Th2-like profile was studied through the quantitative detection of IFN $\gamma$ and IL4 mRNA using the quantitative reverse transcription-polymerase chain reaction (RT-PCR) [8]. Briefly, PBMC were isolated from blood and added to 24 -well plates $\left(3 \times 10^{6}\right.$ cells/well $)$. Incubation at $37{ }^{\circ} \mathrm{C}$ was done for 2 days, in the presence of either phytohemagglutinin (PHA) at $5 \mu \mathrm{g} / \mathrm{mL}$ as a positive control or $100 \mu \mathrm{L}$ of medium as a negative control or $100 \mu \mathrm{L}$ of infectious CSF virus $\left(3 \times 10^{7}\right.$ $\mathrm{TCID}_{50} / \mathrm{mL}$ of cells). Cell mRNA was extracted and IFN $\gamma$ and IL4 mRNA was quantified according to Dufour et al. [8]. The production of IFN $\gamma$ protein by PBMC re-stimulated in vitro was also detected with a commercial interferon kit (Biosource, CA, USA).

\subsubsection{Studies of CSF-specific cytotoxic T lymphocytes}

PBMC were used directly or after in vitro re-stimulation with infectious CSFV $(\mathrm{MOI}=1)$ for 4 days. The cytotoxic activity was determined against CSFV-infected target cells prepared from pig kidney cells of the d/d haplotype (cell line ddK31 kindly supplied by A. Takamatsu, Pirbright, Surrey, UK). Permanently infected ddK31 cells were obtained after three passages with the Alfort virulent strain. The permanent expression of CSFV antigens was confirmed by labeling with an anti-CSFV monoclonal antibody (PPL 282C10A, kindly provided by Merial, France) and subsequent analysis by flow cytometry. CTL activity was measured by flow cytometry as described by Piriou et al. [18]. Briefly, this assay is based on a dual fluorescent staining of target cells. The dye, $\operatorname{DIOC18}_{(3)}$ (Sigma) was used to stain the membrane of target cells and propidium iodide (PI) to label dead target and effector cells. The cytotoxic activity was analyzed by flow cytometry. Spontaneous death cell (low control, LC) was determined by 
Table I. CSFV neutralizing antibodies and detection of virus RNA in blood by RT-PCR in infected or vaccinated pigs.

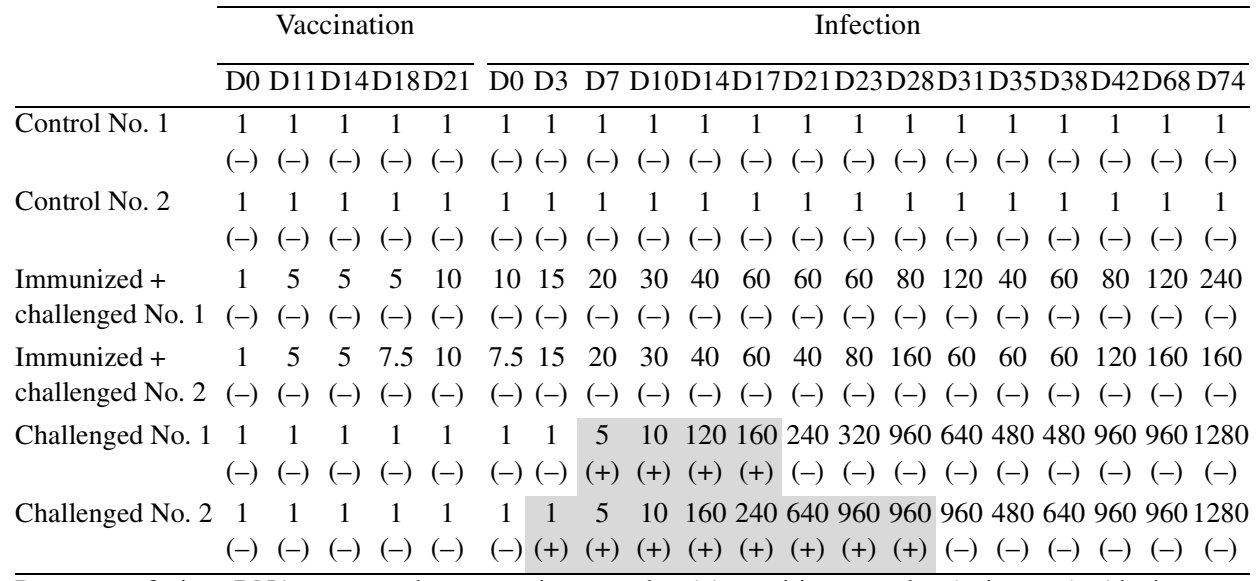

Presence of virus RNA expressed as: negative samples $(-)$; positive samples (+ in grey). Ab titres are expressed as inverse of the last dilution of serum able to neutralize the CSF virus.

incubation at $4{ }^{\circ} \mathrm{C}$ of target and effector cells in order to inhibit effector cell cytotoxic activity. For maximun lysis (high control, HC), target and effector cells were incubated at $37^{\circ} \mathrm{C}$ with $20 \mu \mathrm{L}$ of saponin at $0.3 \mathrm{mg} / \mathrm{mL}$. Results are expressed as percentage of cytotoxicity using the following formula: (\% of target cell lysis in the test $\mathrm{LC}) /(\mathrm{HC}-\mathrm{LC})$.

\section{RESULTS}

Preliminary experiments showed that d/d histocompatible pigs were susceptible to CSFV infection by the Alfort strain, as evidenced by hyperthermia, presence of viral RNA, loss of body weight and reduction in leukocyte counts (data not shown). However, under our experimental conditions, this strain was shown to be of moderate virulence since mortality was only seen on exceptional circumstances.

\subsection{Presence of viral RNA in blood samples after CSFV}

RT-PCR was performed for detection of viral RNA in blood samples. Positive sam- ples for virus RNA were observed from days 3 and 7 PI, up to day 28, in the challenged pigs (Tab. I), which indicates a prolonged viraemia. The challenged animals showed only mild clinical signs, a reduction in food intake but no pyrexia. In contrast, no viral RNA was detected in the blood of the "vacc/chall" and control pigs. This absence of virus replication in vaccinated pigs was in accordance with the absence of clinical signs after challenge. Nevertheless, viral RNA in the "chall" pigs and "vacc/chall" pigs was detected at necropsy.

\subsection{Evolution of blood leukocyte populations after CSFV}

Total leukocyte counts decreased on day 7 PI in the challenged pigs, then returned to initial values at 10 days PI and increased on days 13-17 (Fig. 1). Leukocyte depletions were not as strong as expected, due to the moderate virulence of the challenge virus strain. In contrast, there was no decrease of the leukocyte counts in the "vacc/chall" and control pigs. No modification of leukocyte counts was observed after immunization. The 


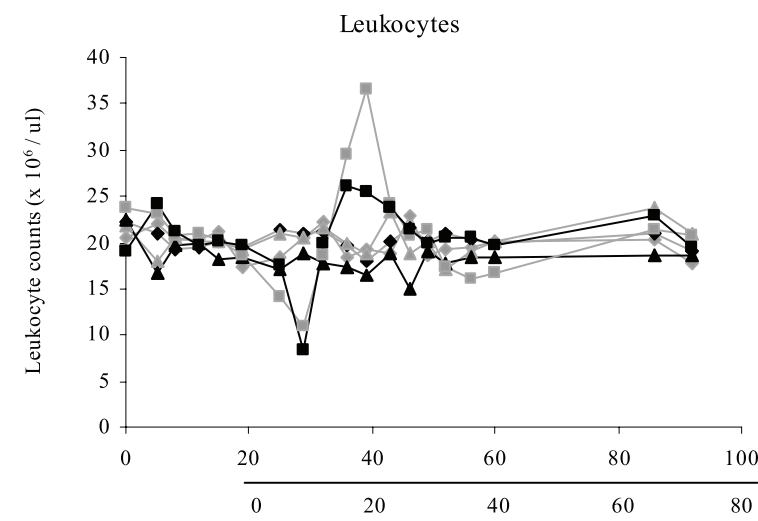

Lymphocytes

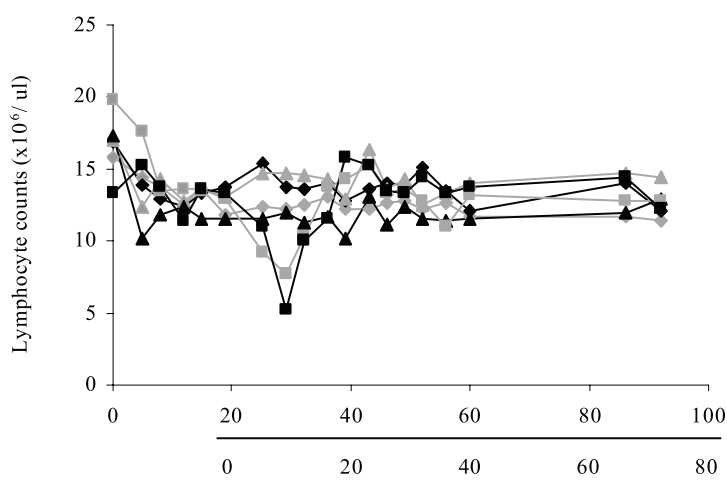

Post immunization days (PID)

Post challenge days (PCD)
Figure 1. Kinetics of blood leukocytes and lymphocytes counts in uninfected control pigs $(\diamond)$, challenged pigs ( $)$ and vaccinated/challenged pigs $(\boldsymbol{\Lambda})$ after CSFV immunization and challenge (PID 21). Each color (black and grey) represents one animal. reduction of leukocyte counts after challenge was time related to the reduction of lymphocyte counts (Fig. 1). At 7 days PI in challenged pigs, the decrease of total lymphocyte numbers was mainly characterized by a drop of $\mathrm{CD} 4^{+} \mathrm{CD} 8^{+}, \mathrm{CD} 4^{+} \mathrm{CD} 8^{-}$ and $\mathrm{CD}^{-}{ }^{-} \mathrm{CD} 8^{+}$cells (Fig. 2).

\subsection{Virus-specific lymphocyte activation and proliferation after CSFV}

Although CSFV infection induced a decreased number of circulating lymphocytes, these cells were still responsive to in vitro antigen stimulation. Lymphocyte activation, as measured in FCM by the expression of membrane IL2-R (CD25), was only detected in challenged pigs, from 10 to 60 days PI (Fig. 3). No lymphocyte activation was detectable in the "vacc/chall" pigs, 3 weeks after vaccination (i.e. day $0 \mathrm{PI}$ ), or after challenge, nor in the control animals. CSFV-driven activation of cells in challenged animals was detected in the $\mathrm{CD}^{-}{ }^{-} \mathrm{CD} 8^{+}$cell subset, with the highest response between 15 and 25 days PI (Fig. 3). A much lower activation was also observed in the $\mathrm{CD} 4{ }^{+} \mathrm{CD} 8^{+}$ cell subset between 35 and 68 days PI. As 

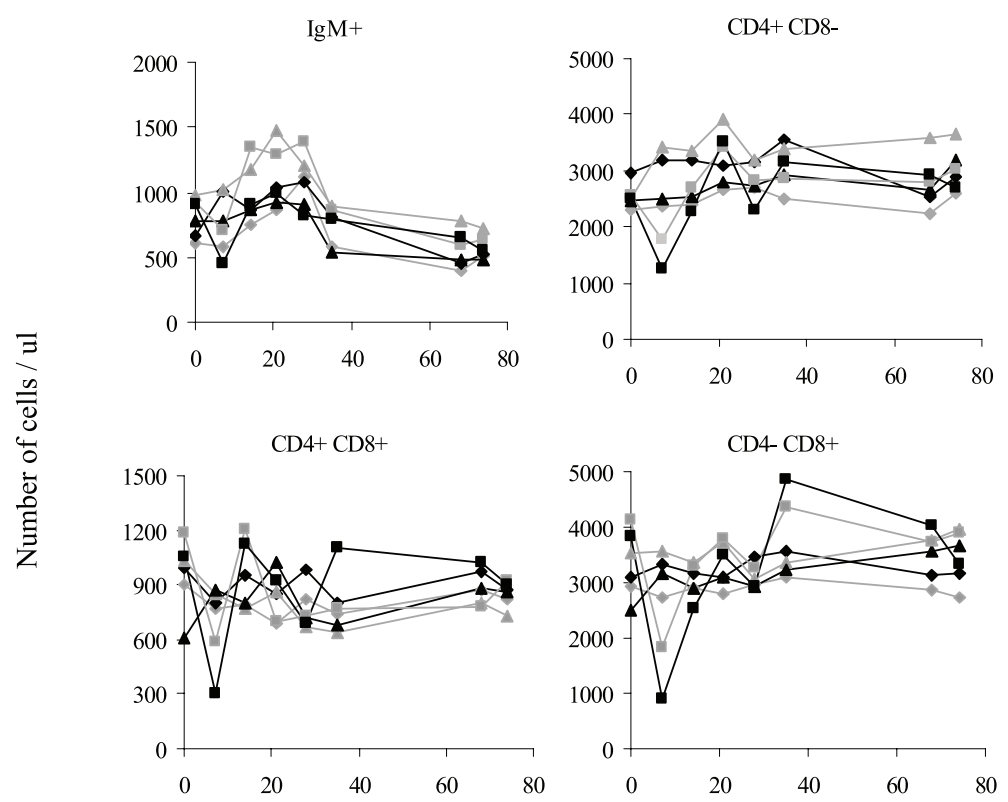

Days PI

Figure 2. Kinetics of lymphocyte cell sub-populations counts after CSFV in uninfected control pigs $(\diamond)$, challenged pigs $(\boldsymbol{\square})$ and vaccinated/challenged pigs $(\boldsymbol{\Delta})$. Each color (black and grey) represents one animal.

expected, we could not detect antigendriven activation of $\mathrm{CD}^{+}{ }^{+} \mathrm{CD} 8^{-}$cells because it is known that this subset acquires CD8 upon activation [22].

CSFV-specific lymphocyte proliferation was also assessed by BRDU incorporation. A positive proliferative response was only observed in one of the two challenged pigs. In this pig, a high proliferative response was detected in $\mathrm{T}$ and $\mathrm{B}$ cell subpopulations, between 25 and 60 days PI. This in vitro proliferation was observed in $\mathrm{CD}^{+}{ }^{+} \mathrm{CD} 8^{-}$and $\mathrm{CD} 4{ }^{-} \mathrm{CD} 8^{+}$cells (Fig. 4). No CSFV-specific lymphocyte proliferation was detected in the "vacc/chall" pigs 3 weeks after vaccination (day 0 PI), or after challenge, nor in control animals. The comparison of BRDU incorporation with CD25 expression showed differences with respect to the kinetic and responding populations. This could be because activation as evidenced by CD25 expression does not necessarily lead to a detectable proliferation, and because not all proliferating cells do express CD25.

\subsection{Specific CTL activity after CSFV}

Cytotoxic T lymphocytes (CTL) were evaluated by flow cytometry using either non-restimulated PBMC or PBMC restimulated in vitro by the virulent Alfort strain for 4 days. Target cells were CSFV infected d/d kidney cells. Controls were also done to assess the non-specific cytolytic activity against non infected target cells. Results in Figure 5a-1 show that nonspecific activity was not observed when PBMC were not re-stimulated in vitro. However, a positive specific primary CTL activity was observed with PBMC collected from one of challenged pigs, at 


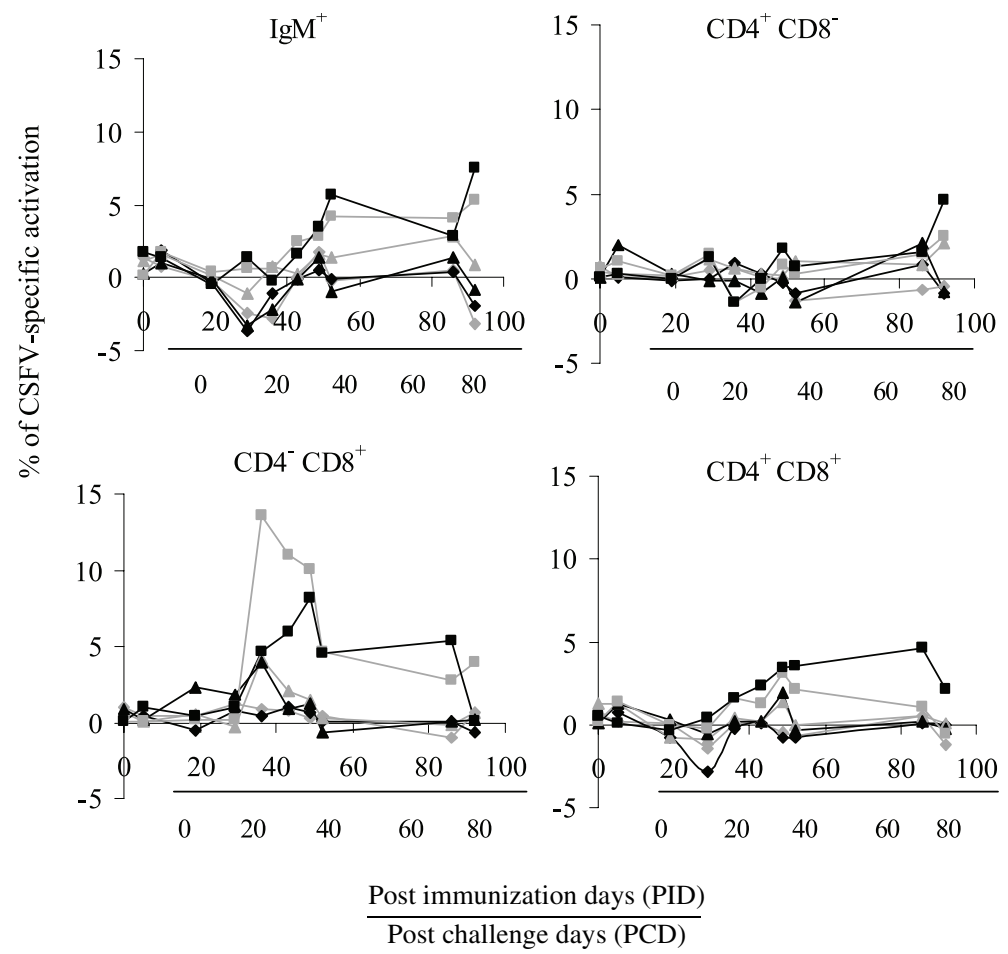

Figure 3. Kinetics of CSFV-specific PBMC activation after infection. Cell activation was measured by IL2R (CD25) expression in cell subsets from uninfected control pigs $(\diamond)$, challenged pigs ( $\mathbf{\square})$ and vaccinated/challenged pigs ( $\boldsymbol{\Delta}$ ) after CSFV immunization and challenge (PID 21). Each color (black and grey) represents one animal. Activation was evaluated after 4 days of in vitro re-stimulation with CSFV, by a double labelling (IgM/CD25) or triple labelling (CD8/CD4/CD25) and subsequent analysis by flow cytometry. Results are expressed as: \% positive cells with CSFV $-\%$ positive cells with control medium.

days 20 to 60 PI (Fig. 5a-2). No primary specific CTL activity was observed in control or vaccinated and challenged animals, at any time after vaccination or challenge. After in vitro re-stimulation with CSFV, a weak non-specific cytotoxicity was observed against uninfected target cells at 40 days PI in the "vacc/chall" and "chall" pigs (Fig. 5b-3). However, a high specific secondary cytotoxic activity was detected in PBMC of challenged pigs by 20 days PI (up to $65 \%$ of cytotoxicity) (Fig. 5b-4). This activity persisted at high levels up to 68 days PI. In contrast, specific secondary cytotoxic activity in the "vacc/chall" pigs was absent 3 weeks after vaccination (day 0 PI), low after challenge. No CTL activity was detected in control animals. At the end of the experiment ( 74 days PI), the level of the specific CTL activity of challenged animals returned to baseline values (Fig. 5).

\subsection{Kinetics of CSFV-induced cytokine expression after infection}

After in vitro re-stimulation of PBMC with infectious virus for 2 days, cell culture supernatants were evaluated for the secretion of IFN $\gamma$ by ELISA and the cells were 


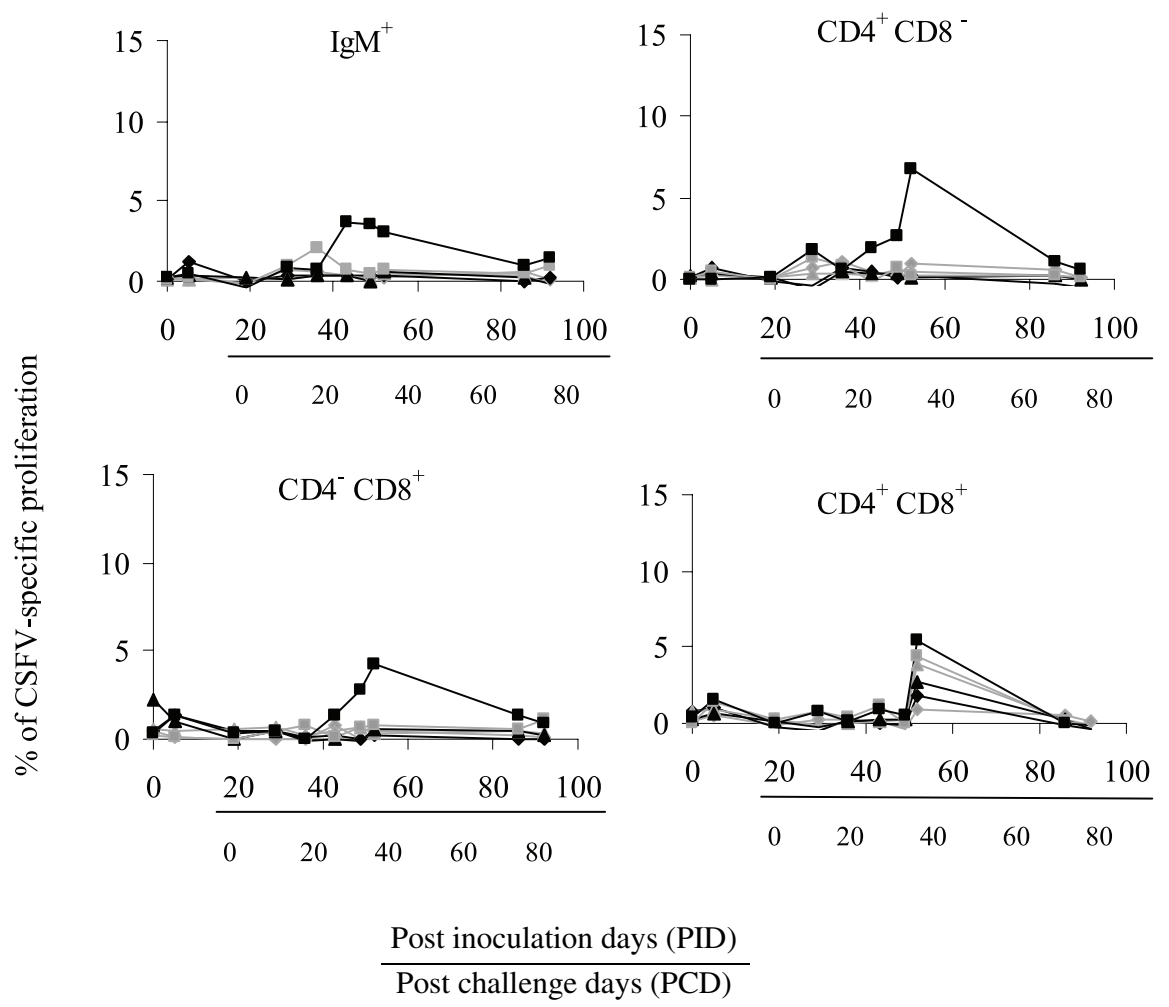

Figure 4. CSFV specific proliferation responses after infection. Lymphoproliferative responses of cell subsets from uninfected control pigs ( $\bullet$ ), challenged pigs ( $(\boldsymbol{\square})$ and vaccinated/challenged pigs (A) after CSFV immunization and challenge (PID 21). Each color (black and grey) represents one animal. This response were evaluated after 4 days of in vitro restimulation with CSFV by BRDU incorporation and subsequent phenotyping by flow cytometry. Results are expressed as: \% BRDU positive cells with CSFV -\% BRDU positive cells with control medium.

treated for the detection of IFN $\gamma$ and IL4 mRNA by quantitative RT-PCR. IFN $\gamma$ mRNA copies were detected in "vacc/ chall" and "chall" pigs (Fig. 6a). The number of IFN $\gamma$ mRNA copies was higher in "chall" pigs compared to "vacc/chall" pigs from day 21 PI onwards. In "vacc/ chall" pigs, IFN $\gamma$ mRNA was detected early after infection, at 7 days PI, suggesting an anamnestic response due to vaccination of those pigs, but no IFN $\gamma$ mRNA was detected 3 weeks after vaccination (day 0 PI). The detection of mRNA IFN $\gamma$ was correlated with the production of IFN $\gamma$ in cell supernatants (Fig. 6a). In contrast to IFN $\gamma$, IL4 mRNA copies were detected only at low levels in all pigs.

\subsection{Antibody responses to CSFV}

CSFV neutralizing serum antibodies were detected 21 days PI in the challenged animals, and 10 days after vaccination in the "vacc/chall" pigs (Tab. I). Although a secondary $\mathrm{Ab}$ production was observed after challenge in the "vacc/chall" pigs, a much higher level of $\mathrm{Ab}$ was reached 
a. primary $\mathrm{CTL}$ activity
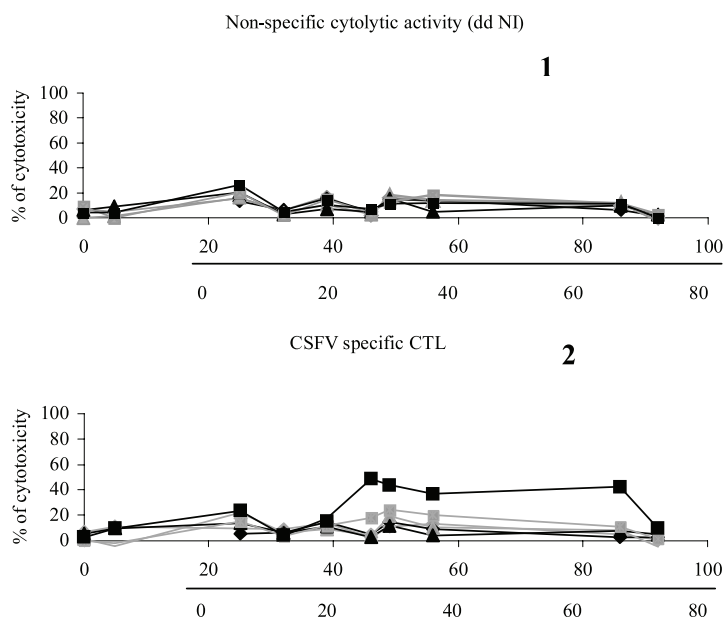

b. secondary CTL activity

Non-specific cytolytic activity (dd NI)

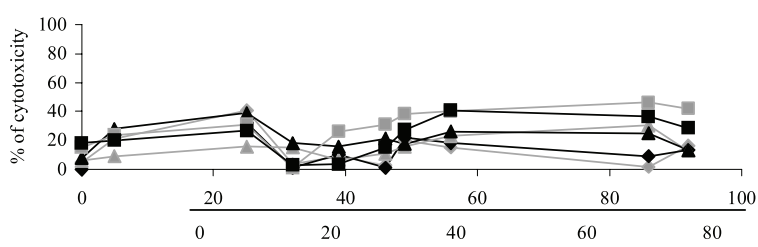

CSFV specific CTL

4

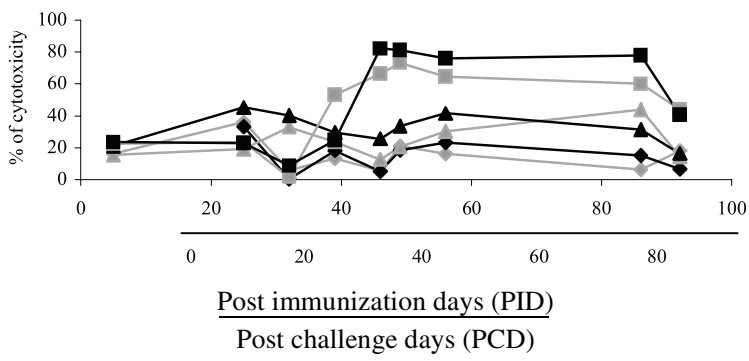

Figure 5. Kinetics of CSFV-specific CTL activity after infection. PBMC were obtained from uninfected control pigs $(\diamond)$, challenged pigs $(\boldsymbol{\square})$ and vaccinated/challenged pigs $(\boldsymbol{\Delta})$ after CSFV immunization and challenge (PID 21). Each color (black and grey) represents one animal. PBMC were assayed in contact for $4 \mathrm{~h}$ with ddK31 kidney cells permanently infected or not with CSFV. The CTL activity was determined against CSFV-infected ddK31 target cells or non-infected target cells (ddNI) (control) by flow cytometry. Results were expressed for an effector/target ratio of 50 $(\mathrm{E} / \mathrm{T}=50)$. a. Primary CTL activity (without CSFV in vitro restimulation); b. Secondary CTL activity (after CSFV in vitro restimulation). $\mathbf{1}$ and $\mathbf{3}$ : cytotoxic activity against non infected $\mathrm{d} / \mathrm{d}$ target cells; 2 and 4: CSFV specific CTL. 

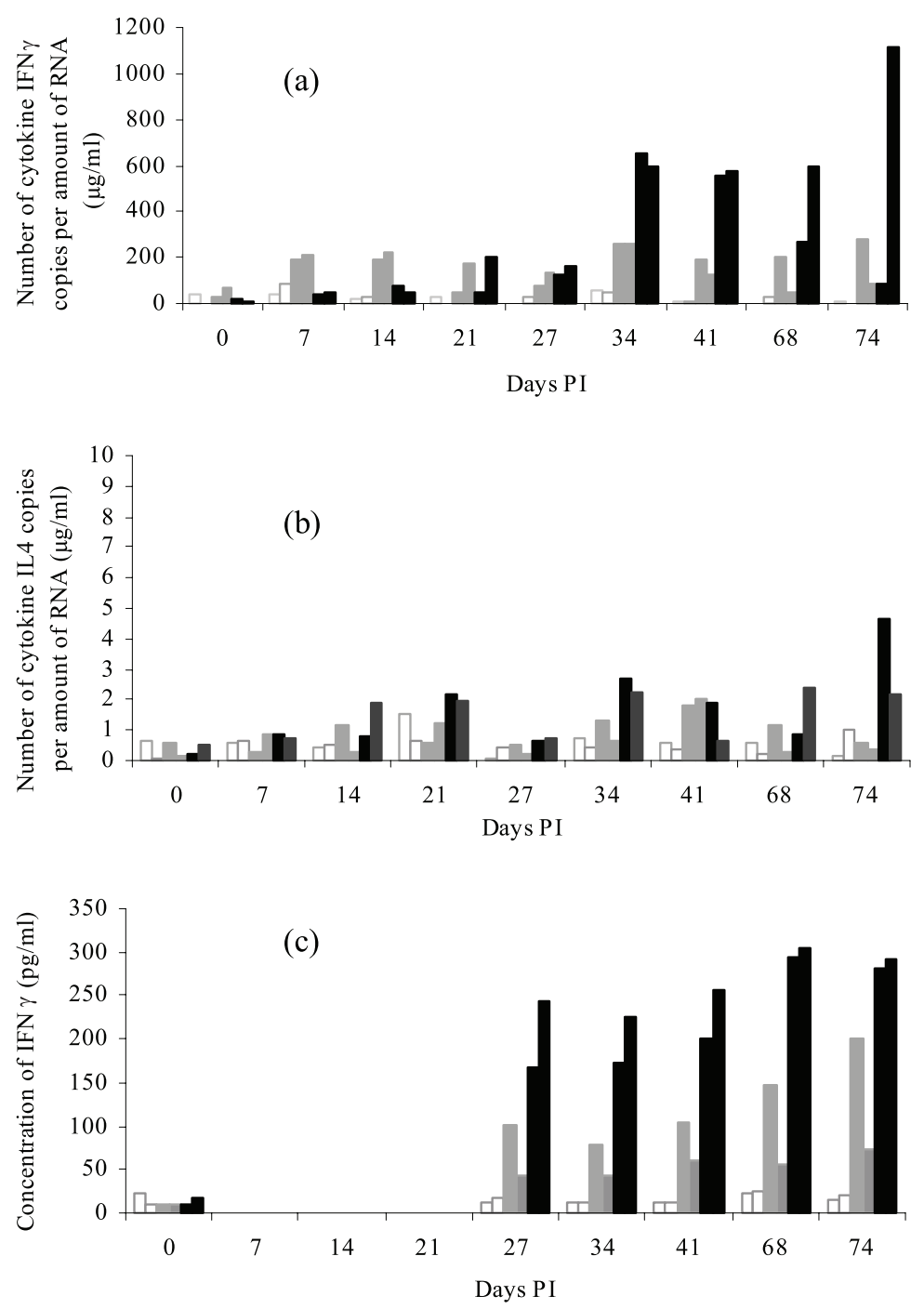

Figure 6. Kinetics of CSFV-induced IFN $\gamma$ and IL4 production by PBMC. IFN $\gamma$ (a) and IL4 (b) mRNA expression (RT-PCR) in PBMC and IFN $\gamma$ expression (ELISA) in supernatants of PBMC (c) following in vitro restimulation for 2 days with CSFV. PBMC from uninfected control pigs (white), challenged pigs (black) and vaccinated/challenged pigs (grey). The results of negative controls were 2 copies for IFN $\gamma, 1$ for IL4, and $4 \mathrm{pg} / \mathrm{ml} \mathrm{IFN} \gamma$ as detected by ELISA.

in the non vaccinated challenged animals (Tab. I). Three weeks after vaccination in the "vacc/chall" pigs (day $0 \mathrm{PI}$ ), a low antiCSFV IgG response was detected which increased after challenge, again suggesting an anamnestic response (Fig. 7). In the challenged pigs, higher CSF-specific IgG, IgG1 and IgA responses were observed from day $21 \mathrm{PI}$, as compared to the "vacc/ chall" pigs. 


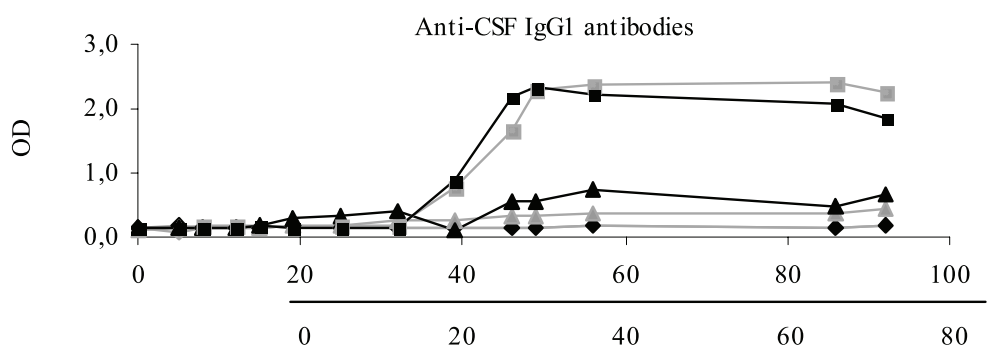

Anti-CSF IgG2 antibodies
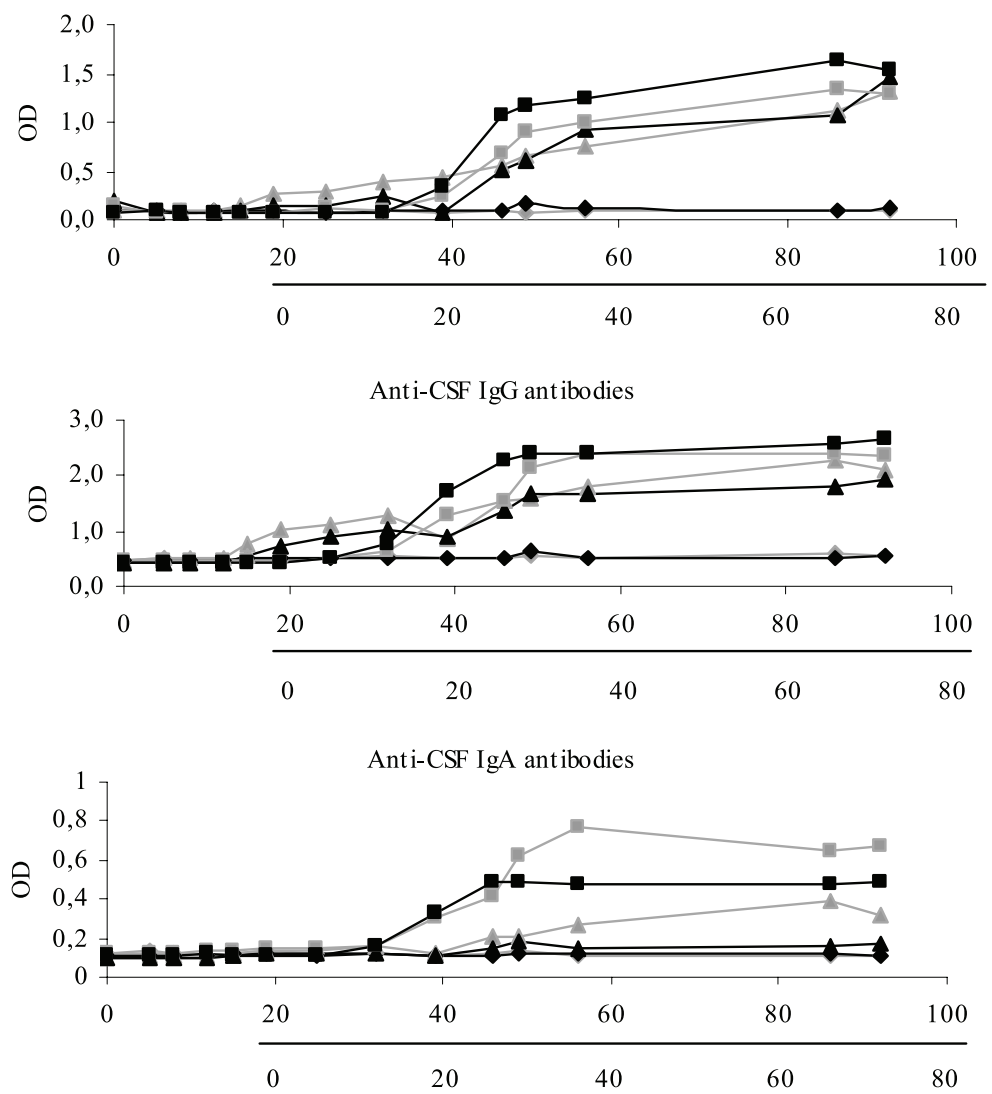

$\underline{\text { Post immunization days (PID) }}$

Post challenge days (PCD)

Figure 7. Kinetics of anti-CSFV IgG (on the top-left panel), IgA (on the top-right panel), IgG1 (left panel) and IgG2 (right panel) in uninfected control pigs $(\bullet)$, challenged pigs $(\boldsymbol{\nabla})$ and vaccinated/ challenged pigs ( $\boldsymbol{\Delta})$ after CSFV immunization and challenge (PID 21). Each color (black and grey) represents one animal. Anti-CSFV IgG subclasses were measured by indirect ELISA on microtitration plates coated with CSFV antigen. 


\section{DISCUSSION}

The objective of this study was to analyze in details the kinetics of cell-mediated immune responses to CSFV, including antigen-driven activation and proliferation of lymphocyte subsets, primary and secondary specific CTL activity and cytokine responses. In order to conduct CTL assays, histocompatible $\mathrm{d} / \mathrm{d}$ pigs were used. To perform a prolonged kinetic study of immune responses after infection, early death of the animals after CSFV challenge had to be avoided. We therefore decided to infect pigs by the oronasal route with a low dose of virus $\left(10^{4.5} \mathrm{TCID}_{50}\right.$ of the virulent Alfort strain). In these pigs, we observed only mild clinical signs: a reduction in food intake, no pyrexia, along with a drop in blood leukocyte counts 7 days PI. Although the challenge was moderate, viral RNA was detected in blood from 3-7 days PI up to 28 days PI in the "chall" pigs. On the other hand, we also used in two other pigs, a IM vaccination three weeks after challenge with the Alfort strain to induce a strong immune response against CSFV. In contrast with the previous pigs, those pigs were protected against the challenge, as shown by the absence of any clinical signs, virus replication and drop of leukocyte counts. The blood leukocyte depletion after infection of non vaccinated animals corresponded to a specific reduction of $\mathrm{CD}^{+}$and/or $\mathrm{CD} 8^{+} \mathrm{T}$ cells. These results were in accordance with the reports of Summerfield et al. [25] and Lee et al. [10] who described a depletion of CD4 T cells during acute CSF, and with the data from Markowska-Daniel et al. [12] showing a strong depletion of $\mathrm{CD}^{+}$. However, this observation contrasted with the results of Susa et al. [28] where the B cell subset was more affected than the $\mathrm{T}$ cell subsets.

The end-point for viral RNA detection coincided with the presence of high titers of serum neutralizing antibodies. However, titers were always lower in the "vacc/chall" pigs compared to the "chall" pigs. This could be due to the reduction of virus replication in the vaccinated pigs, leading to a reduced immune stimulation after challenge. The same difference was seen on IgG (IgG1) and IgA by ELISA. The challenge by the oronasal route without prior immunization gave substantial amounts of circulating CSFV-specific IgA. IgG1 and IgG2 antibody responses were differentially modulated in the two groups of animals, which may reflect different "Th1/Th2" like modulations depending upon immunization protocols. While infected pigs developped a strong IgG1 and $\mathrm{IgG} 2$ response, the "vacc/chall" animals only displayed IgG2 responses. Together with the high IFN- $\gamma$ and cytotoxic responses, this would indicate that infection of pigs is more associated with the Th1 responses compared to the "vacc/chall" protocol. However, the concept of "Th1/Th2" balance is not yet well documented in pigs.

A major focus was made on kinetics of cell-mediated immune responses: CSFVspecific activation of $\mathrm{CD}^{-}{ }^{-} \mathrm{CD} 8^{+} \mathrm{T}$ cells was observed early post-infection in the "chall" pigs. In addition, $\mathrm{CD} 4{ }^{+} \mathrm{CD} 8^{+} \mathrm{T}$-cells, considered as memory $\mathrm{T}$ cells $[26,35]$ were also activated later on. Interestingly, we could not detect activation of $\mathrm{CD} 4^{+} \mathrm{CD} 8^{-}$ cells. Surprisingly, only one of the "chall" pigs showed a high CSFV-specific proliferation response. With this pig, an early activation of $\mathrm{CD}^{-}{ }^{-} \mathrm{CD} 8^{+}$cells and a high specific CTL response was induced. Surprisingly, in this pig, the CSFV-specific proliferative response was also observed in $\mathrm{IgM}^{+} \mathrm{B}$ cells. Among $\mathrm{T}$ cell subsets, both $\mathrm{CD}^{+} \mathrm{T}$ cells and $\mathrm{CD} 8^{+} \mathrm{T}$ cells were induced to proliferate after re-stimulation with the virulent CSFV strain. Our results are divergent from those of Kimman et al. [9] who showed that mainly $\mathrm{CD}^{+}$cells proliferate while $\mathrm{CD}^{+}{ }^{+}$do not. The difference may be due to the methods or the protocols used. We used a direct labeling of proliferating cells while Kimman et al. [9] depleted different cell subsets before detection of proliferation by tritiated thymidine incorporation. Compared to challenged 
animals, vaccination did not induce detectable activation of lymphocytes within 3 weeks after vaccination, nor after challenge.

Primary CSFV-specific CTLs, i.e. without any in vitro re-stimulation by the virus, were found in PBMC of one "chall" pig. These circulating CTLs, were highly active at 3 weeks PI and then persisted up to 74 days PI. They may play a role in vivo for clearing virus-infected cells and thus enabling the infected pigs to control CSFV replication by days 21 to 28 post-infection as shown by the results of RNA detection, and finally to escape the development of a chronic infection. Such a high and prolonged level of primary CTL activity was constrasting with the report of Pauly et al. [15] in which repeated infections of pigs and in vitro re-stimulation were necessary for generating virus-specific CTLs. In our study, the in vitro re-stimulation increased the CTL activity in the two "chall" pigs but not in the others. This might relate to the route of vaccination or challenge which was different. Interestingly, this CTL activity was concomitant with the production of IFN $\gamma$ in re-stimulated $\mathrm{T}$ cells. A recent publication of Suradhat et al. [27] showed the high IFN $\gamma$ production following CSFV infection. This IFN $\gamma$ production may contribute to the generation of CTL as observed in our study. We provide here a clear connection between the two responses thus showing that the detection of IFN $\gamma$ may be a good indicator of CTL response in pigs.

In conclusion, we show that a single infection with the Alfort virulent strain by the oronasal route was able to induce important CSFV-specific cell-mediated immune responses in $\mathrm{d} / \mathrm{d}$ histocompatible pigs: activation and proliferation of $\mathrm{CD} 4^{+} \mathrm{CD}^{+}$, $\mathrm{CD} 4^{+} \mathrm{CD} 8^{-}$and $\mathrm{CD} 4^{-} \mathrm{CD} 8^{+}$cells, production of IFN $\gamma$ and generation of CTL. These responses were absent after intramuscular vaccination with an attenuated virus and considerably lower after challenge of vaccinated pigs. Thus, although this vaccina- tion could protect animals to challenge and induce antibodies, it did not induce detectable T-cell responses. It also became clear from this study that the influence of intramuscular compared to intranasal vaccination or challenge requires further consideration. In a preliminary study of passive transfer of protection to $\mathrm{CSFV}$ in $\mathrm{d} / \mathrm{d}$ pigs, donor $\mathrm{CD} 2^{+}$ cells from vaccinated pigs were indeed unable to protect recipient pigs from virus challenge, whereas the immune serum, as expected, did it [19]. Therefore, our findings of high cell-mediated and humoral responses after infection by the oronasal route reinforce the need to develop new strategies for vaccine improvement, specifically in view of the development of high cell mediated responses in the context of deleted or marker vaccines. Such vaccines are awaited for use under emergency conditions, to allow rapid discrimination between infected and vaccinated pigs [6, 31]. Subunit vaccines were recently developed for that purpose [4] but proved to be of moderate efficacy under emergency [7, 30]. The methods that we developed in our study will help future identifications of new CSFV antigens as powerful targets for CTL and T-cell responses, likely prerequisites for the rationale development of improved marker vaccines.

\section{ACKNOWLEDGEMENTS}

We are grateful to Mr. Roland Cariolet and Gerard Bennevent for their assistance during the experiment.

\section{REFERENCES}

[1] Adriaansen H.J., Osman C., Van Dongen J.J.M., Wijdenes-de-Bresser J.H.F.M., Kappetijn-Van Tilborg C.M.J.M., Hooijaas H., Immunological marker analysis of mitogen-induced proliferation lymphocytes using BrdU incorporation or screening of metaphases. Staphylococcal protein $\mathrm{A}$ is a potent mitogen for CD4+ lymphocytes, Scand. J. Immunol. 32 (1990) 687-694. 
[2] Bailey M., Stevens K, Bland P.W., Stokes C.R., A monoclonal antibody recognising an epitope associated with pig interleukin-2 receptors, J. Immunol. Methods 153 (1992) 85-91.

[3] Beer M., Wolf G., Pichler J., Wolfmeyer A., Kaaden O.-R., Cytotoxic T-lymphocyte responses in cattle infected with bovine viral diarrhea virus, Vet. Microbiol. 58 (1997) 9-22.

[4] Bouma A., De Smit A.J., De Jong M.C., De Kluijver E.P., Moormann R.J., Determination of the onset of the herd-immunity induced by the E2 sub-unit vaccine against classical swine fever virus, Vaccine 18 (2000) 1374-1381.

[5] Charley B., Corthier G., Houdayer M., Rouzé P., Modifications des réactions immunitaires au cours de la peste porcine classique, Ann. Rech. Vet. 11 (1980) 27-33.

[6] De Smit A.J., Bouma A., De Kluijver E.P., Terpstra C., Moormann R.J.M., Duration of the protection of an E2 subunit marker vaccine against classical swine fever after a single vaccination, Vet. Microbiol. 78 (2001) 307-317.

[7] Depner K.R., Bouma A., Koenen F., Klinkenberg D., Lange E., de Smit H., Vanderhallen H., Classical swine fever (CSF) marker vaccine. Trial II. Challenge study in pregnant sows, Vet. Microbiol. 83 (2001) 107-120.

[8] Dufour V., Arnauld C., Lantz O., Peguilet I., Morvilliers K., Albina E., Jestin A., Quantification of porcine cytokine gene expression using RT-PCR, a homologous internal control and chemiluminescence for microplate detection, J. Immunol. Methods 229 (1999) 49-60.

[9] Kimman T.G., Bianchi A.T., Wensvoort G., de Bruin T.G., Meliefste C., Cellular immune response to hog cholera virus (HCV): $\mathrm{T}$ cells of immune pigs proliferate in vitro upon stimulation with live $\mathrm{HCV}$, but the E1 envelope glycoprotein is not a major T-cell antigen, J. Virol. 67 (1993) 2922-2927.

[10] Lee W.C., Wang C.S., Chien M.S., Virus antigen expression and alterations in peripheral blood mononuclear cell subpopulations after classical swine fever virus infection, Vet. Microbiol. (1999) 17-29.

[11] Liess B., Prager D., Detection of neutralising antibodies (NIF) test: use of new technical equipment for laboratory swine fever diagnosis, CEC Seminar on diagnosis and epizootiology of classical swine fever, 1976.
[12] Markowska-Daniel I., Pejsak Z., Winnicka A., Collins R.A., Phenotypic analysis of peripheral leukocytes in piglets infected with classical swine fever virus, Res. Vet. Sci. 67 (1999) 53-57.

[13] Martins C.L.V., Lawman M.J.P., Scholl T., Mebus C.A., Lunney J.K., African swine fever virus specific porcine cytotoxic $\mathrm{T}$ cell activity, Arch. Virol. (1993) 211-225.

[14] McGoldrick A., Bensaude E., Ibata G., Sharp G., Paton D.J., Closed one-tube reverse transcription nested polymerase chain reaction for the detection of pestiviral RNA with fluorescent probes, J. Virol. Methods 79 (1999) 85-95.

[15] Pauly T., Elbers K., Konig M., Lengsfeld T., Saalmuller A., Thiel H.J., Classical swine fever virus-specific cytotoxic T lymphocytes and identification of a T cell epitope, J. Gen. Virol. 76 (1995) 3039-3049.

[16] Pelliciari C., Mangiarotti R., Bottone M.G., Danova M., Wang E., Identification of resting cells by dual parameter flow cytometry of statin expression and DNA content, Cytometry 21 (1995) 329-337.

[17] Pescovitz M.D., Lunney J.K., Sachs D.H., Preparation and characterization of monoclonal antibodies reactive with porcine PBL, J. Immunol. 133 (1984) 368-375.

[18] Piriou L., Chilmonczyk S., Genetet N., Albina E., Design of a flow cytometry assay for the determination of natural killer and cytotoxic T-lymphocyte activity in Human and in different animal species, Cytometry 41 (2000) 289-297.

[19] Piriou L., Hutet E., Chevallier S., Saintilan A.F., Legal S., Le Potier M.F., Albina E., Protection against classical swine fever virus infection conferred by antibodies or T lymphocytes after transfer in inbred pigs, 5th international congress of the European society for veterinary virology, Brescia, Italy, 2000 (abstract).

[20] Ressang A.A., Van Bekkum J.G., The indirect fluorescent antibody technique as a method for detecting serum antibodies against hog cholera. Part 1. An outline of the technique and its prelimination evaluation, Zentrabl. Veterinaermed. Beih. 16 (1972) 709-716.

[21] Rumenapf T., Stark R., Meyers G., Thiel H.J., Structural proteins of hog cholera virus expressed by vaccinia virus: further characterization and induction of protective immunity, J. Virol. 65 (1991) 589-597.

[22] Saalmüller A., Pauly T., Hohlich B.J., Pfaff E., Characterization of porcine $\mathrm{T}$ lymphocytes 
and their immune response against viral antigens, J. Biotechnol. 73 (1999) 223-233.

[23] Saalmüller A., Werner T., Fachinger V., T-helper cells from naive to committed, Vet. Immunol. Immunopathol. 87 (2002) 137145.

[24] Summerfield A., Knotig S.M., McCullough K.C., Lymphocyte apoptosis during classical swine fever: implication of activationinduced cell death, J. Virol. 72 (1998) 18531861.

[25] Summerfield A., Mcneilly F., Walker I., Allan G., Knoetig S.M., Mccullough K.C., Depletion of $\mathrm{CD}^{+}$and $\mathrm{CD} 8^{+} \mathrm{T}$-cells before the onset of viraemia during classical swine fever, Vet. Immunol. Immunopathol. 78 (2001) 3-19.

[26] Summerfield A., Rziha H.J., Saalmüller A., Functional characterization of porcine $\mathrm{CD}^{+}$ $\mathrm{CD}^{+}$extrathymic $\mathrm{T}$ lymphocytes, Cell. Immunol. 168 (1996) 291-296.

[27] Suradhat S., Intrakamhaeng M., Damrongwatanapokin S., The correlation of virus-specific interferon-gamma production and protection against classical swine fever virus infection, Vet. Immunol. Immunopathol. 83 (2001) 177-189.

[28] Susa M., Konig M., Saalmüller A., Reddehase M.J., Thiel H.J., Pathogenesis of classical swine fever: B-lymphocyte deficiency caused by hog cholera virus, J. Virol. 66 (1992) 1171-1175.
[29] Terpstra C., Wensvoort G., The protective value of vaccine-induced neutralising antibody titres in swine fever, Vet. Microbiol. 16 (1988) 123-128.

[30] Uttenthal A., Le Potier M., Romero L., De Mia G.M., Floegel-Niesmann G., Classical swine fever (CSF) marker vaccine. Trial I. Challenge studies in weaner pigs, Vet. Microbiol. 83 (2001) 85-106.

[31] Van Oirschot J.T., Diva vaccines that reduce virus transmission, J. Biotechnol. 73 (1999) 195-205.

[32] Van Oirschot J.T., Effect of infections with swine fever virus on immune functions. III. Antibody response to lipopolysaccharide and sheep red blood cells, Vet. Microbiol. 8 (1983) 97-103.

[33] Wengler G., Family Flaviviridae. In classification and nomenclature of viruses, in Francki C.M.F.R.I.B., Knudson D.L., Brown F. (Eds.), Fifth report of the international committee of the taxonomy of viruses, Berlin, springer verlag, 1991.

[34] Woldehiwet Z., Sharma R., Alterations in lymphocyte subpopumations in peripheral blood of sheep persistently infected with border disease virus, Vet. Microbiol. (1990) $153-160$.

[35] Zuckermann F.A., Husmann R.J., Functional and phenotypic analysis of porcine peripheral blood CD4/CD8 double-positive T cells, Immunology 87 (1996) 500-512. 